\title{
PRÁTICAS DE GEOGRAFIA: A ESCOLA COMUM E A ESCOLA DE SURDOS NA PERCEPÇÃO DOS ESTUDANTES ${ }^{1}$
}

\author{
Fernanda Santos Pena \\ Prefeitura Municipal de Uberlândia. \\ E-mail: fernandapena.edu@gmail.com \\ Adriany de Ávila Melo Sampaio \\ Universidade Federal de Uberlândia - UFU. \\ E-mail: adrianyavila@gmail.com
}

\begin{abstract}
RESUMO
Apesar das políticas de inclusão priorizarem a matrícula dos estudantes surdos na escola comum, o movimento surdo reivindica a criação e a manutenção das Escolas de Surdos. Observa-se a necessidade de pesquisar como está sendo realizado o ensino e a aprendizagem nesses dois espaços, para que os estudantes surdos sejam melhor atendidos. O objetivo geral deste trabalho é analisar como o ensino de Geografia está sendo realizado na Escola Comum e nas Escolas de Surdos, pelo uso da pesquisa qualitativa. Foram aplicados questionários com 42 estudantes surdos do $9^{\circ}$ ano do Ensino Fundamental, no âmbito de cinco Escolas de Surdos, localizadas nos estados de Minas Gerais, São Paulo, Goiás e no Distrito Federal. O estudo verificou que a maioria dos estudantes pesquisados considerou que a aprendizagem nas Escolas de Surdos é ótima, justificando que os professores se comunicam e ministram aulas em Libras, além de utilizarem recursos didáticos que exploram a visualidade, como o computador, projetor multimídia, TV, Internet, mapas, imagens, dentre outros. Já na escola comum, as práticas pedagógicas realizadas pelos professores de Geografia são direcionadas para os estudantes ouvintes e não incluem os surdos em suas especificidades linguísticas e culturais. Concluiu-se que o ensino de Geografia realizado na Escola Bilíngue de Surdos, com professores de Geografia formados na área, proficientes em Libras e com conhecimentos metodológicos para surdos, é realizado de modo satisfatório.
\end{abstract}

Palavras-chave: Metodologias de ensino. Professor de Geografia. Recursos didáticos.

\section{INTRODUÇÃO}

Cada vez mais, a Geografia escolar vem se colocando como uma área de conhecimento envolvida socialmente com a produção da condição humana e com a produção consciente dos espaços, sejam eles naturais, sociais, culturais ou políticos. A aprendizagem de Geografia na educação básica contribui para a formação de uma consciência espacial, desde suas dimensões locais às mais globais, assim como de cidadania, sendo comprometida com a realidade socioespacial.

Essa ciência é um instrumento curricular que possibilita aos estudantes surdos conhecer, analisar, interpretar e agir na realidade espacial construída e materializada

\footnotetext{
${ }^{1}$ Este trabalho é parte da Tese de Doutorado "Educação Bilíngue e Geografia nas Escolas de Surdos", com autoria de Fernanda Santos Pena e orientação de Adriany de Ávila Melo Sampaio, defendida no Instituto de Geografia da Universidade Federal de Uberlândia, em 2018.
} 
como produto e processo das relações socioespaciais. Para que ocorra um melhor ensino e aprendizado dos conhecimentos geográficos, é preciso verificar como esse grupo de estudantes percebe a Geografia e compreende melhor os seus conceitos.

O presente trabalho considera que a opinião e os sentimentos dos estudantes precisam ser conhecidos e analisados. No que tange ao ensino e à aprendizagem de Geografia, foram aplicados questionários em cinco Escolas de Surdos, localizadas nos estados de Minas Gerais, São Paulo, Goiás e no Distrito Federal, durante pesquisas de campo realizadas pela pesquisadora, na construção de sua tese. Participaram os alunos do $9^{\circ}$ ano do Ensino Fundamental, por entender-se que eles possuem mais experiências e vivências, quando comparados aos alunos dos anos anteriores.

Os questionários foram aplicados pela pesquisadora, no espaço escolar, durante as aulas de Geografia. Respeitando-se a língua natural dos surdos, as questões foram interpretadas em Língua Brasileira de Sinais (Libras) e os estudantes foram auxiliados durante o seu preenchimento. Muitas vezes, quando desconheciam a palavra que queriam expressar, respondiam em Libras para que a pesquisadora ou os professores pudessem transcrever para a Língua Portuguesa, sem comprometer o conteúdo das respostas.

As ideias dos estudantes foram transcritas neste trabalho de acordo com a norma gramatical da Língua Portuguesa, para melhor entendimento das respostas, pois a escrita dos surdos apresenta particularidades relacionadas à língua de sinais, as quais podem incidir na estrutura sintática da Língua Portuguesa.

A quantidade de estudantes surdos participantes variou para cada escola, conforme observado no quadro 1 , uma vez que foi considerado na pesquisa o número total de alunos frequentes no $9^{\circ}$ ano. Participaram da pesquisa 42 estudantes surdos, sendo que 23 eram do sexo masculino e 19 do sexo feminino. A idade variou entre $14 \mathrm{e}$ 26 anos, sendo que a maioria dos estudantes possuía entre 15 (29\%) e 16 anos (21\%). 
Quadro 1 - Estudantes surdos participantes da pesquisa

\begin{tabular}{|c|c|}
\hline Escola / Instituto & $\begin{array}{c}\text { Quantidade de } \\
\text { estudantes }\end{array}$ \\
\hline Escola para Surdos Dulce de Oliveira & 8 \\
\hline Instituto Santa Inês & 5 \\
\hline Escola Bilíngue Libras e Português-Escrito & 6 \\
\hline Centro Especial Elysio Campos & 7 \\
\hline Instituto SELI & 16 \\
\hline Total & $\mathbf{4 2}$ \\
\hline
\end{tabular}

Fonte: PENA, F. S. (2018).

Considerando que a escola comum é onde a maioria dos estudantes surdos brasileiros está matriculada, durante a pesquisa foram analisadas não apenas as percepções dos pesquisados com relação à Escola de Surdos, mas também da escola que o MEC, atualmente, considera como ideal para a inclusão escolar dos surdos. Buscouse comparar as opiniões sobre as duas escolas, na perspectiva de analisar melhor os sentimentos dos estudantes e as práticas de Geografia realizadas.

Na pesquisa, os estudantes foram identificados pelas siglas E1, E2, E3, e, assim, sucessivamente, na intenção de preservar suas identidades e as escolas onde estudam. A seguir, são analisadas as informações obtidas com base nos questionários, enfatizandose as concepções dos estudantes surdos sobre as práticas pedagógicas e o ensino de Geografia, considerando o trabalho docente dos professores, os recursos didáticos, as metodologias de ensino utilizadas, e as avaliações, na escola comum e na Escola de Surdos.

\section{PRÁTICAS DE GEOGRAFIA NA ESCOLA COMUM}

Com relação à Escola Comum, onze estudantes tiveram aulas com professores de conteúdo específico, pois estudaram nos anos finais do Ensino Fundamental. Dentre eles, nove informaram que o professor de Geografia não sabia Libras e dois que o professor sabia alguns sinais.

A estudante E15 considerou que: Tinha intérprete, mas eu aprendia pouco, não entendia. (E15). 
Sobre os relacionamentos dos professores de Geografia com os estudantes surdos, a maioria também informou que não existia ou que era "ruim". Apenas dois falaram que era "bom", justificando com o esforço do professor para que aprendessem. Um exemplo expressivo foi a seguinte ideia: Não conseguia aprender. O professor só oralizava e passava textos. (E8).

Quando questionados sobre as práticas de ensino dos professores de Geografia, citaram: "livro", “intérprete”, “quadro", “caderno", “desenho”. Uma aluna afirmou que a professora: Ensinava igual aos ouvintes, como se eu fosse ouvinte também. (E16).

Sobre a forma como eram avaliados na escola comum, apenas dois estudantes disseram que eram avaliados utilizando a Libras. Um estudante afirmou que: Eu explicava em Libras e depois respondia em Português. (E20).

Muitos estudantes falaram sobre a dificuldade com as atividades avaliativas, assim como observado nas opiniões:

Bem, os professores avaliavam a minha escrita, o que eu respondia nas atividades, provas, etc.

Não conhecia as palavras em Português, era difícil. Matemática era fácil. (E21).

Eu estudava muito em casa, memorizando. (E30).

Difícil. (E18).

Não usava Libras. Eu tinha nota ruim. (E16). Não tinha Libras. Minhas notas eram baixas. (E27). A prova era escrita, eu tentava fazer um pouco. (E8).

Com relação aos conhecimentos de Geografia aprendidos na escola comum, 15 estudantes responderam à questão, sendo que 73\% responderam que aprenderam pouco os conhecimentos de Geografia na escola comum, 14\% que aprenderam e 13\% que não aprenderam.

De modo geral, observa-se que o ensino de Geografia na escola comum vem ocorrendo insatisfatoriamente. A própria inserção do surdo no ambiente escolar, junto com ouvintes, tendo a Língua Portuguesa como língua de instrução, faz com que os surdos se sintam sozinhos e abandonados. Geralmente, não estabelecem relacionamento com os professores e estudantes ouvintes, por não dominarem a Libras.

$\mathrm{Na}$ escola comum, as práticas pedagógicas realizadas pelos professores de Geografia são direcionadas para os estudantes ouvintes. As avaliações, por exemplo, são elaboradas e aplicadas na Língua Portuguesa escrita, o que não propicia aos estudantes surdos demonstrarem os seus conhecimentos geográficos aprendidos. Diante do insucesso escolar, com as notas baixas, muitos professores permitem que os estudantes 
surdos copiem as respostas, ou, até mesmo, distribuem nota sem a devida avaliação dos seus conhecimentos, assim como exposto pela estudante surda.

A professora me deixava copiar a prova dos amigos do lado. (E34).

O gráfico 1 apresenta os dados relatados.

Gráfico 1- Aprendizagem dos conhecimentos geográficos na Escola Comum

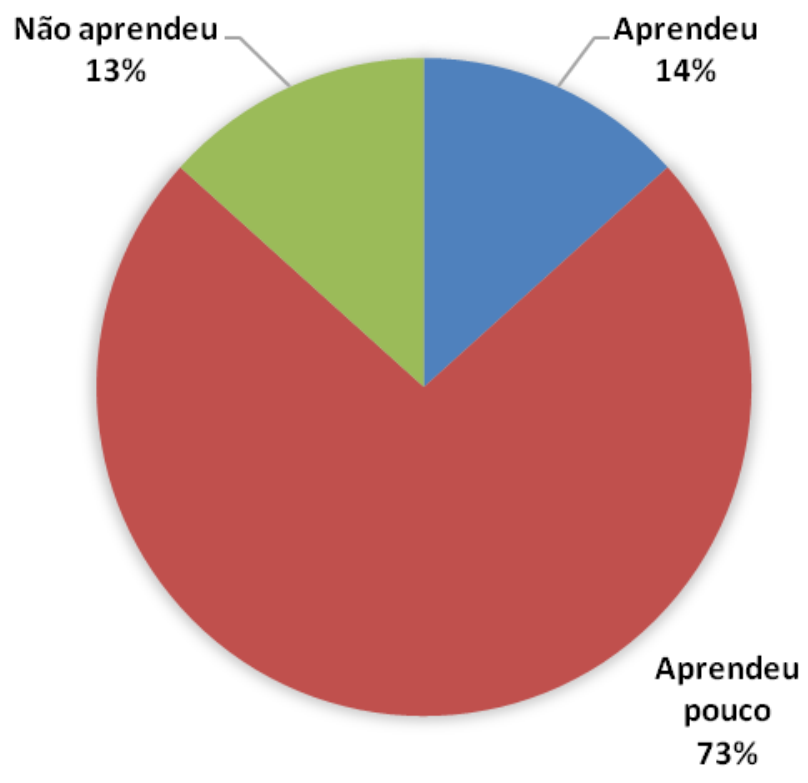

Fonte: PENA, F. S. (2018).

Ao justificarem sua aprendizagem, os estudantes destacaram as ideias:

Aprendia pouco, só copiava do quadro. (E3). Não muito, porque o professor explicava muito rápido, mas entendia um pouco. (E14). Muito não, porque só copiava os textos. Eu decorava os países, climas, etc. (E12).

Esse tipo de atitude assistencialista tira o direito dos surdos de aprender, pois eles não recebem uma educação adequada para as suas diferenças linguísticas e culturais, não aprendem e, mesmo assim, são avaliados como aptos para ingressarem no próximo ano escolar. Igualmente como mostrou o gráfico 1, a maioria dos estudantes acredita ter aprendido pouco os conhecimentos geográficos, ensinados na escola comum. Eles memorizavam alguns nomes, sem compreender de forma crítica os conceitos que estavam sendo ensinados. 


\section{ENSINO E APRENDIZAGEM DE GEOGRAFIA NA ESCOLA DE SURDOS}

Com relação à Escola de Surdos, inicialmente, os estudantes pesquisados responderam sobre o domínio da Libras, o relacionamento com os alunos e as práticas de ensino dos professores de Geografia.

Dentre os estudantes surdos, $67 \%$ responderam que os professores de Geografia possuem o domínio da Libras. Os outros 33\% afirmaram que dominam mais ou menos. Deve-se considerar que todos os professores eram ouvintes, sendo a Libras a L2 para eles.

O relacionamento desses professores com os alunos, de maneira geral, era próspero. A maioria dos estudantes qualificou os professores como "amigos". Também houve destaque para "ajuda", "legal", "conversa" e "ótimo". Em menor frequência, apareceu: "tira dúvidas", "ensina bem" e "melhorando". Uma aluna informou que: "bom, a gente ajuda a professora para melhorar a comunicação em Libras" (E14).

Sobre as práticas de ensino de Geografia realizadas pelos professores, foram citadas a utilização de vídeo, mapas, computador, jornais, livros, revistas, filme, Internet, projetor multimídia, desenho, quadro, caderno, e Libras. O aluno E11 afirmou que "a professora fala e ensina em Libras. Os alunos entendem muito bem". Também se destacaram as ideias:

Ensina sobre tudo de Geografia. (E12).

Precisa ensinar mais palavras. (E23).

Bom, ela explica bem as palavras de Geografia que não conhecemos. (E17). Ótimo. A professora explica tudo e eu aprendo tudo. (E15).

Os estudantes pesquisados mencionaram materiais didáticos de Geografia que possibilitavam uma melhor aprendizagem. O gráfico 2 apresenta a quantidade que cada um foi citado. 
Gráfico 2 - Materiais e recursos didáticos para o ensino de Geografia, de acordo com os estudantes pesquisados

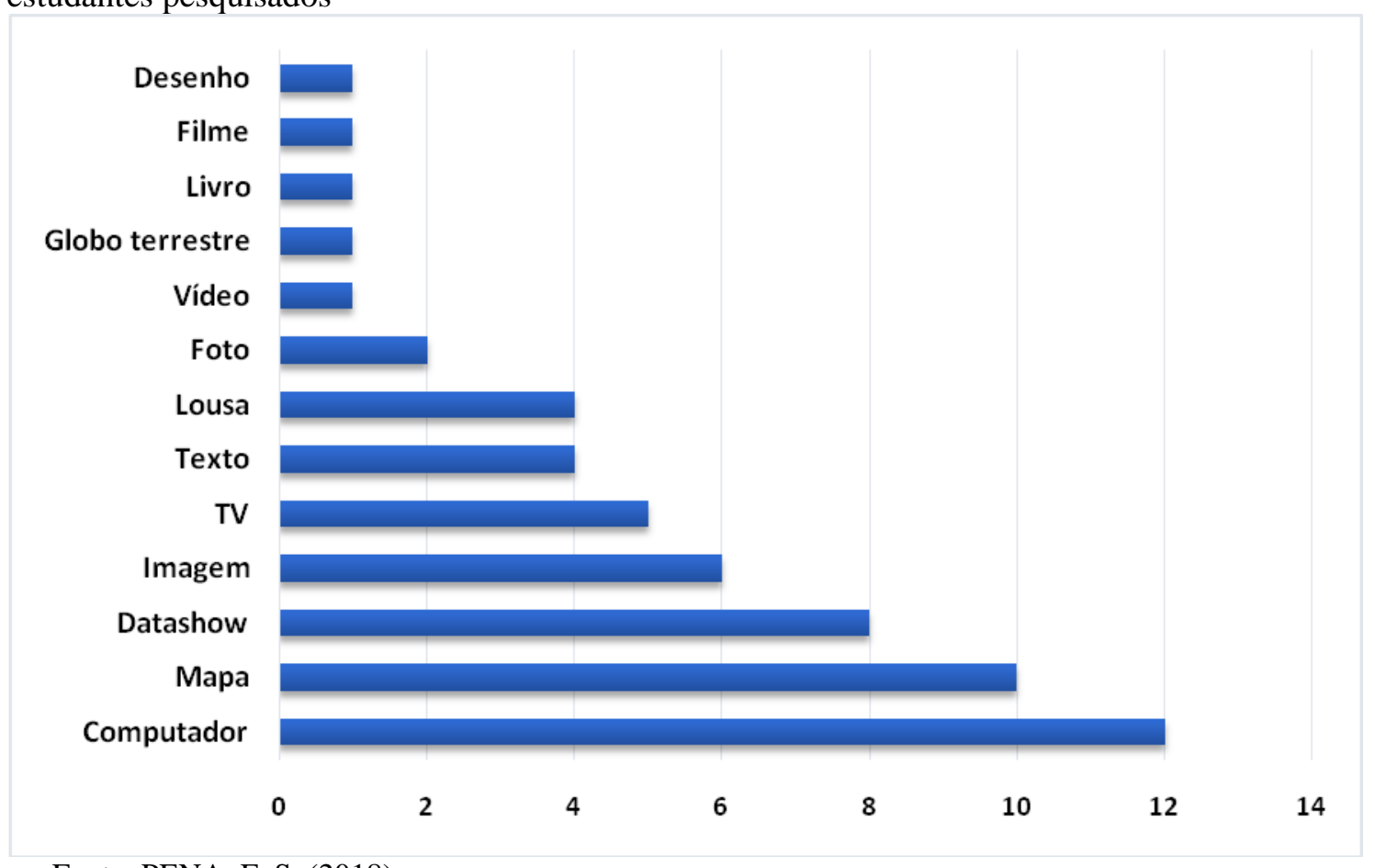

Fonte: PENA, F. S. (2018).

O computador foi o recurso mais citado pelos estudantes, aparecendo doze vezes nos questionários. O mapa foi relatado por dez estudantes. Também houve destaque para o projetor multimídia, para as imagens e para a TV. Texto e lousa foram citados por quatro estudantes, cada um, seguido pela foto, vídeo, globo terrestre, livro, filme e desenho.

Todos os materiais e recursos apresentados pelos estudantes surdos podem explorar a visualidade. $\mathrm{O}$ resultado da questão afirmou o que muitos pesquisadores de educação para surdos têm defendido: a importância em se utilizar recursos visuais para a aprendizagem dos diversos conhecimentos. Observa-se que os recursos apresentados podem ser utilizados na Escola de Surdos e na escola comum, pois são de interesse de todos os alunos.

Também é importante pensar que a visualidade, por si só, não garante a aprendizagem. Supõe-se práticas imagéticas mediadas, uma vez que o professor precisa contextualizar e criar significados para o que é apresentado, em Libras. A aluna E22 destacou: Deve usar paisagem e foto, como na realidade. (E22). 
Os estudantes foram questionados sobre como deveria ser a aula de Geografia para que eles pudessem aprender melhor. A maioria citou a necessidade do professor realizar aulas em Libras. A aluna E15 destacou: Usando Libras eu acho que não preciso de mais coisas, porque já é suficiente, aprendo muito mais. (E15).

Também foram citados os estudos de continentes, países, estados, espaços geográficos e atualidades.

Gosto de estudar o Mundo, o Brasil, e os estados. (E4). É importante Geografia do Brasil, própria para conhecer os lugares. (E23).

Nota-se que os conteúdos geográficos despertam interesse nos estudantes surdos, facilitando a sua aprendizagem. Cabe ao professor planejar e ministrar aulas que utilizem recursos didático-pedagógicos baseados na visualidade, juntamente com a Libras e a realidade dos seus estudantes.

Com relação às avaliações de Geografia, os estudantes pesquisados afirmaram que os seus conhecimentos são mais bem mensurados por meio das provas em Libras, na Língua Portuguesa escrita com imagem, nos trabalhos e atividades.

Observa-se que os estudantes consideram a importância das avaliações em Libras sem, contudo, desconsiderar a necessária aprendizagem escolar do português. $\mathrm{Na}$ perspectiva bilíngue, é fundamental a participação das duas línguas na escola, em todo o processo de escolarização.

Os estudantes surdos também foram questionados se aprendem bem os conhecimentos de Geografia na Escola de Surdos. Em três escolas foi unânime a resposta de que "sim", aprendem muito. Em uma escola um estudante respondeu que "médio" e, em outra, dois disseram que "médio" e um que "pouco".

Observam-se as seguintes ideias:

Aprendo palavras, sinais e mais conhecimento. (E34).

Aqui é melhor, aprendo rápido, pois entendo a Libras que a professora fala. (E13). Sim, porque não precisamos copiar tanto, a professora explica bem com as imagens. (E17).

É fácil com Libras. (E1).

Aprendo porque a professora explica bem. Quando eu não entendo, eu pergunto a ela. (E36). Sim, minha nota é boa. (E19).

No gráfico 3 é possível verificar a porcentagem de estudantes, sobre a aprendizagem dos conhecimentos geográficos. Assim como observado, a maioria dos 
estudantes surdos (86\%) afirmou que aprende muito os conhecimentos geográficos na Escola de Surdos.

Gráfico 3 - Aprendizagem dos conhecimentos geográficos nas Escolas de Surdos, segundo os estudantes pesquisados

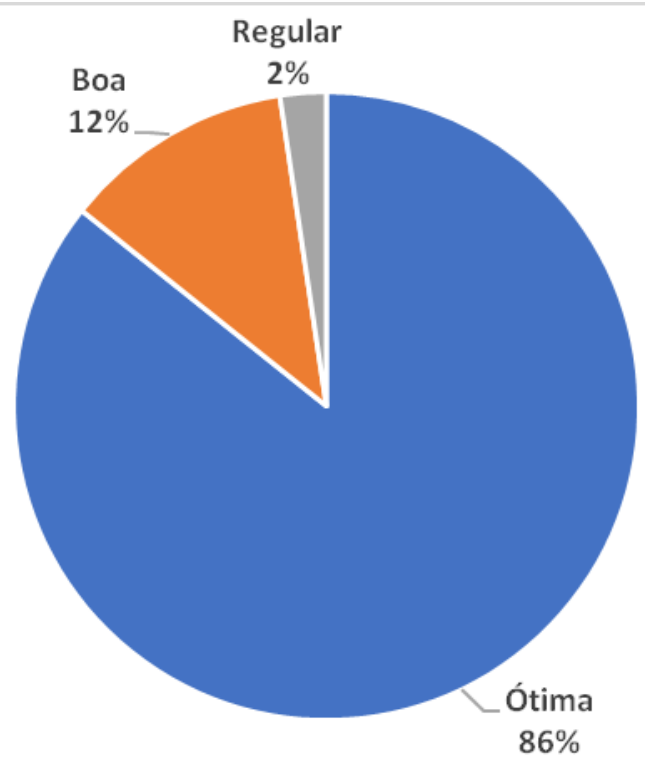

Fonte: PENA, F. S. (2018).

Os estudantes justificaram suas respostas informando que a Libras possibilita um aprendizado melhor para eles, tendo em vista que os professores de Geografia explicam e esclarecem dúvidas do conteúdo por meio dela, sem a necessidade de uma terceira pessoa - o intérprete. Além de aprenderem os conhecimentos geográficos, eles aprendem novos sinais da Libras e palavras da Língua Portuguesa, próprias da área geográfica e do cotidiano.

Outra questão a ser analisada é a de que "não precisamos copiar tanto". $\mathrm{Na}$ escola comum, geralmente, os professores solicitam aos seus alunos muitas cópias do quadro negro, de textos, nas atividades e trabalhos.

Para os estudantes surdos, as cópias não têm significado e sentido, pois a maioria não interpreta os textos extensos, quando se está lendo ou escrevendo, sendo necessária a tradução para a Libras.

$\mathrm{Na}$ Escola de Surdos, os professores possuem a tendência de trabalhar com imagens e textos menores. As palavras-chave e conceitos podem ser explicados em Libras, para que o estudante faça a associação. Desse modo, eles não irão apenas copiálos, mas compreendê-los. 
Um estudante que afirmou aprender "médio" justificou que: Sei poucas palavras, aprendo mais ou menos. (E14).

A afirmação representa o pouco domínio da Língua Portuguesa escrita e a associação de que apenas pode aprender por meio dela, desconsiderando os conhecimentos adquiridos em Libras. Assim como a maioria dos educadores ouvintes, ele avalia seus próprios conhecimentos por meio do domínio da leitura e da escrita em português somente.

O estudante que afirmou aprender "pouco" não justificou o porquê. Cabe ressaltar que o mesmo apresentava deficiência intelectual e dificuldade motora, o que demandava maior tempo para o aprendizado.

Sobre a importância de aprender Geografia, as respostas variaram em alguns aspectos: a importância de conhecer os estados e países; de conhecer as diferenças percebidas pelo mundo; de conhecer novas palavras e significados; e de estudar para ter um futuro melhor, seja por meio da faculdade e/ou de emprego. Nenhum estudante disse não serem importantes os conhecimentos geográficos.

Destacaram-se as seguintes opiniões:

É importante estudar. Aprofundar assuntos sobre estados e países. (E7). Para conhecer os estados, países, capitais, todos tipos de Geografia. (E17). Sim, aprendo palavras novas, leio textos, conheço países. (E14). Para aprender a estudar o mundo, os países. (E23). Para conhecer os lugares do mundo. (E12). Aprender diferentes coisas do mundo todo. (E22). Geografia é importante, porque aprendi sobre mapas, textos, e a professora explicou muito. (E9).

Para ver o que o mundo é, o que acontece com os climas de cada país. O mundo é diferente.

Às vezes tem palavra difícil, mas é bom aprender, é importante. (E24). Aprendi sobre São Paulo e Brasil. (E33).

Os estudantes surdos, assim como os estudantes ouvintes, possuem curiosidade para conhecer lugares novos, por seus diferentes aspectos naturais, sociais e econômicos. Durante o Ensino Fundamental, a Geografia possibilita o estudo da cidade, do campo, dos estados brasileiros, dos países e continentes, do Planeta Terra, dentre outros, em suas diferentes características. Também permite aos estudantes conhecerem melhor o lugar onde vivem, podendo despertar o senso de pertencimento e de cidadãos 
participativos. Conhecer o mundo, por meio de imagens, mapas, vídeos, textos e demais recursos didático-pedagógicos é fundamental para todos os estudantes.

\section{CONSIDERAÇÕES FINAIS}

A partir das informações obtidas, verificou-se que, de modo geral, o ensino de Geografia na escola comum vem ocorrendo insatisfatoriamente, sendo que a maioria dos estudantes acredita ter aprendido pouco os conhecimentos geográficos. Por outro lado, os estudantes surdos se sentem pertencentes às Escolas de Surdos, gostam dos professores bilíngues, dos amigos surdos e, principalmente, de vivenciarem o aprendizado por meio da Libras. A maioria afirmou que aprende bem os conhecimentos geográficos estudados nessa escola e que consideram esses conhecimentos significativos.

Nas Escolas de Surdos são utilizados recursos didáticos visuais, aliados aos conhecimentos geográficos e pedagógicos dos professores, com aulas expositivas/dialogadas em Libras, a partir da experiência visual dos surdos.

Os estudantes surdos pesquisados enfatizaram a importância de se conhecer o mundo e as diversidades dos países, estados, cidades e seus diferentes lugares. Os recursos didáticos visuais foram eleitos como os mais promissores, sendo que os mapas foram um dos recursos mais citados por eles, assim como as imagens e as tecnologias de informação e comunicação.

\section{REFERÊNCIAS}

PENA, Fernanda Santos. Educação Bilíngue e Geografia nas escolas de surdos. 258 f. Tese (Doutorado em Geografia) - Instituto de Geografia, Universidade Federal de Uberlândia, Uberlândia, 2018. Disponível em: <http://dx.doi.org/10.14393/ufu.te.2018.630>. Acesso em: 08 de outubro de 2020. 